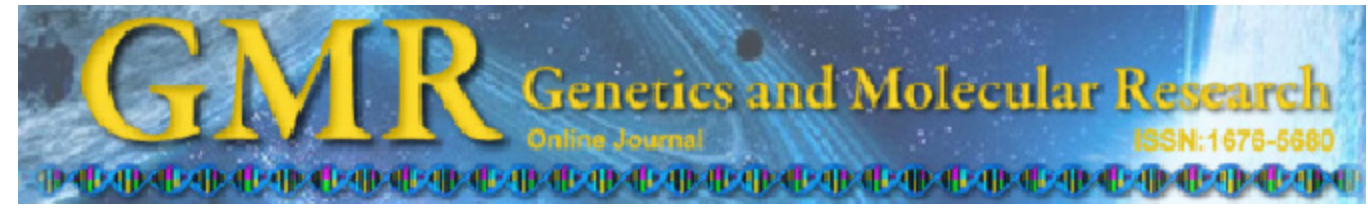

\title{
Pulmonary hypertension in patients with stage 1-3 chronic kidney disease
}

\author{
Q.M. Yang and X.R. Bao \\ Department of Nephrology, Jinshan Hospital, Fudan University, \\ Shanghai, China \\ Corresponding author: X.R. Bao \\ E-mail: XiaorongBAOcn@163.com
}

Genet. Mol. Res. 13 (3): 5695-5703 (2014)

Received March 6, 2014

Accepted June 25, 2014

Published July 25, 2014

DOI http://dx.doi.org/10.4238/2014.July.25.25

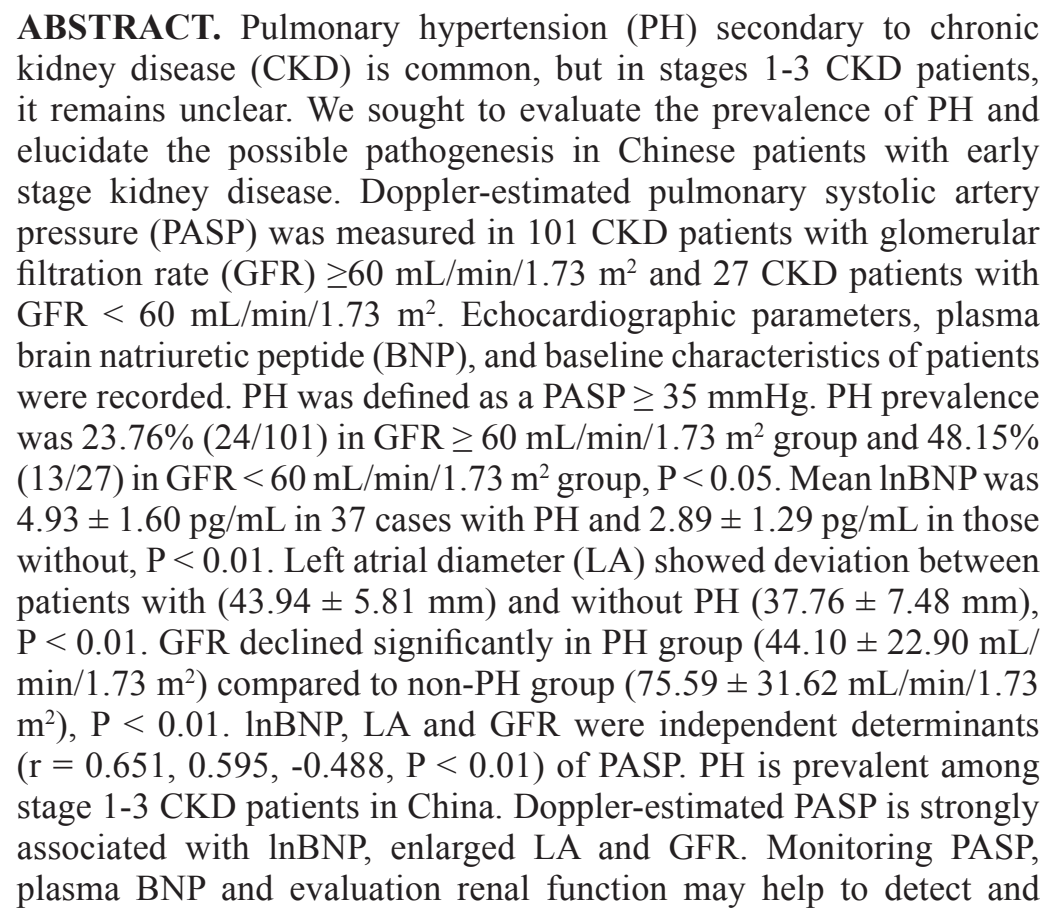


prevent severe $\mathrm{PH}$ in $\mathrm{CKD}$.

Key words: Pulmonary hypertension; Pulmonary artery pressure; Chronic kidney disease

\section{INTRODUCTION}

Pulmonary hypertension $(\mathrm{PH})$ has been traditionally defined as a mean pulmonary artery pressure of at least $25 \mathrm{mmHg}$ at rest, with a pulmonary capillary wedge pressure of 15 $\mathrm{mmHg}$ or less. Significant PH can cause deterioration of right ventricular function, precipitating hemodynamic collapse and death (Rich, 1988).

$\mathrm{PH}$ has been increasingly recognized in patients with chronic kidney disease (CKD), and is not simply confined to those with connective tissue and systemic diseases. PH in patients with CKD may be induced and/or aggravated by left ventricular (LV) disorders as well as the presence of risk factors typical to CKD, including volume overload, an arteriovenous fistula (Abdelwhab and Elshinnawy, 2008), sleep-disordered breathing (Sakaguchi et al., 2011), exposure to dialysis membranes (Kiykim et al., 2010), endothelial dysfunction (Zoccali, 2007), vascular calcification and stiffening, and severe anemia (Buemi et al., 2007). Preventing PH in this population is crucial, as even kidney transplantation may not reverse the high mortality associated with PH. Therefore, greater emphasis needs to be placed on CKD patients, even during early stages of the disease.

However, there is no data on the prevalence of $\mathrm{PH}$ in patients with stage 1-3 CKD [according to Kidney Disease Outcomes Quality Initiative (KDOQI)]. The pathogenesis of PH in this group of patients is not explained satisfactorily. Based on a retrospective analysis of 128 CKD patients, this article investigates the pulmonary artery systolic pressure (PASP) change pattern and its relationship with cardiovascular structure and function, in order to strengthen the understanding of $\mathrm{PH}$ and its relevant mechanisms in earlier stages of CKD.

\section{MATERIAL AND METHODS}

\section{Material selection}

Pre-dialysis patients with CKD were included during January 2008 to December 2010. The etiologies for CKD included primary glomerulonephritis (IgA nephropathy, membrane nephropathy, focal segmental glomerular sclerosis, etc.), diabetic kidney disease, and chronic ischemic renal disease. Patients with thoracic or lung disease, left-right shunt congenital heart disease, connective tissue disease, appetite inhibitive medications history (e.g., fenfluramine, dexamphetamine), erythropoietin history and HIV infection history were excluded. All patients had complete demographic data and underwent echocardiography.

\section{Clinical and laboratory investigations}

Patient data on baseline characteristics [age, gender, height, weight, body mass index (BMI), medication used] and kidney disease (etiology of renal disease) were recorded. Brain natriuretic peptide (BNP) in EDTA-anticoagulated venous blood was tested by Triage from Biosite. Glomerular filtration rate (GFR) was measured using ${ }^{99 \mathrm{~m}} \mathrm{Tc}-\mathrm{DTPA}$.

Doppler echocardiography was performed by one experienced operator using Vivid 7 
Pro with 3S probe with 1.5-3.6 MHz image frequency and 1.8-2 MHz Doppler frequency (General Electric Co., USA). Two-dimensional and M-mode echocardiography was performed. A tricuspid systolic jet was recorded from the parasternal or apical window with the continuouswave Doppler probe. The PASP or systolic right ventricular pressure was calculated using the Bernoulli equation: PASP $=4 \times$ (tricuspid systolic jet $)^{2}+10 \mathrm{mmHg}$ (estimated right atrial pressure) (Berger et al., 1985). PH was defined as a PASP $\geq 35 \mathrm{mmHg}$ (Reisner et al., 1994).

\section{Data analysis}

All statistical analysis were performed using the SPSS 13.0 software. Continuous variables are reported as means \pm standard deviation. Non-normal distributed variables were transformed into normal style. Unpaired two tailed $t$-test and chi-squared test were generated between group comparison. Linear regression analysis was realized between PASP with both echocardiography data and lnBNP, leading to Pearson's correlation coefficient. Figures performed using Microsoft Excel 2010. P values less than 0.05 were considered to be statistically significant.

\section{RESULTS}

There were 62 men and 66 women with a mean age of $53.39 \pm 17.52$ years (range 1797). In patients with GFR $\geq 60 \mathrm{~mL} / \mathrm{min} / 1.73 \mathrm{~m}^{2}$ (mean $77.52 \pm 26.95 \mathrm{~mL} / \mathrm{min} / 1.73 \mathrm{~m}^{2}$ ), there were 45 men and 56 women with a mean age of $51.50 \pm 16.57$ years (range 17-86). In patients with GFR $<60 \mathrm{~mL} / \mathrm{min} / 1.73 \mathrm{~m}^{2}$ (mean $21.93 \pm 9.36 \mathrm{~mL} / \mathrm{min} / 1.73 \mathrm{~m}^{2}$ ), there were $17 \mathrm{men}$ and 10 women with a mean age of $61.41 \pm 19.06$ years (range 24-97). The etiologies of kidney injury were primary glomerulonephritis (IgA nephropathy, membrane nephropathy, and focal segmental glomerular sclerosis), diabetic kidney disease, and chronic ischemic renal disease. The mean PASP was $32.37 \pm 8.55 \mathrm{mmHg}$ (range $0-62$ ). PH incidence was $28.91 \%(37 / 128)$ overall, with $23.76 \%(24 / 101)$ in GFR $\geq 60 \mathrm{~mL} / \mathrm{min} / 1.73 \mathrm{~m}^{2}$ group and $48.15 \%(13 / 27)$ in GFR $<60 \mathrm{~mL} / \mathrm{min} / 1.73 \mathrm{~m}^{2}$ group. Demographic values were not significantly different between GFR $\geq 60 \mathrm{~mL} / \mathrm{min} / 1.73 \mathrm{~m}^{2}$ patients and GFR $<60 \mathrm{~mL} / \mathrm{min} / 1.73 \mathrm{~m}^{2}$ patients. There was no significant difference between GFR $\geq 60 \mathrm{~mL} / \mathrm{min} / 1.73 \mathrm{~m}^{2}$ and GFR $<60 \mathrm{~mL} / \mathrm{min} / 1.73 \mathrm{~m}^{2}$ groups according to echocardiography findings [LV end-diastolic (LVDd), LV end-systolic (LVDs), interventricular septum thickness (IVST), LV post wall (LVPW), LV ejection fraction (LVEF), and LV mass index (LVMI)], mean artery blood pressure (MAP), and BMI. The mean values of $\operatorname{lnBNP}$ and left atrial diameter (LA) showed obvious differences between patients with GFR $\geq 60 \mathrm{~mL} / \mathrm{min} / 1.73 \mathrm{~m}^{2}$ and patients with GFR $<60 \mathrm{~mL} / \mathrm{min} / 1.73 \mathrm{~m}^{2}$. The former valued $3.20 \pm 1.52 \mathrm{pg} / \mathrm{mL}$ and $39.54 \pm 5.81 \mathrm{~mm}$, and the latter, $4.60 \pm 1.75 \mathrm{pg} / \mathrm{mL}$ and 42.19 $\pm 5.96 \mathrm{~mm}$ (Table 1).

The mean PASP in 37 patients was $\geq 35 \mathrm{mmHg}$, ranging from 35 to $62 \mathrm{mmHg}$. There were no differences between patients with $\mathrm{PH}$ and patients without $\mathrm{PH}$ according to gender ratio and BMI. In patients with $\mathrm{PH}$, there were 23 men and 14 women with a mean age of $65.16 \pm 15.39$ years (range 30-97). In patients without $\mathrm{PH}, 39$ men and 52 women with a mean age of $48.88 \pm 16.15$ years (range 17-86). GFR declined significantly in PH group patients with a mean of $44.10 \pm 22.90 \mathrm{~mL} / \mathrm{min} / 1.73 \mathrm{~m}^{2}$ (range $6.70-78.50$ ), when compared to non-PH group patients, with a mean of $75.59 \pm 31.62 \mathrm{~mL} / \mathrm{min} / 1.73 \mathrm{~m}^{2}$ (range 14.70-183.00). PH group patients exhibited higher MAP of $166.15 \pm 31.46 \mathrm{mmHg}$ than the non-PH group, at $146.99 \pm$ $28.53 \mathrm{mmHg}$. The mean $\operatorname{lnBNP}$ was $4.93 \pm 1.60 \mathrm{pg} / \mathrm{mL}$ in 37 cases with PH, $2.89 \pm 1.29 \mathrm{pg} / \mathrm{mL}$ 
in cases with PASP $<35 \mathrm{mmHg}$. Doppler echocardiography in the PH cases (e.g., LVDd, LVDs, IVST, LVPW, LVEF) showed significant deviation from the non-PH group. The LVMI was also significantly different between the two groups (Table 2). The PASP showed a positive correlation with patient age, InBNP, diameters of LVDd, LVDs, IVST, LVPW, and LVMI. However, the PASP had a negative correlation with GFR and LVEF. By linear regression analysis, with PASP as dependent variable and the above factors as covariates, we found independent determinants for PASP, $\operatorname{lnBNP}, \mathrm{LA}$, and GFR. The regression equation was $\mathrm{PASP}=3.637+2.536 \mathrm{x}$ $\operatorname{lnBNP}+0.622 \times$ LA $-0.075 \times$ GFR $(\mathrm{F}=20.944, \mathrm{P}<0.001)($ Table 3, Figure 1).

Table 1. Patients' demographics.

\begin{tabular}{|c|c|c|c|}
\hline Variables & Patients with GFR $\geq 60 \mathrm{~mL} / \mathrm{min}$ & Patients with GFR $<60 \mathrm{~mL} / \mathrm{min}$ & $P$ value \\
\hline No. of patients & 101 & 27 & \\
\hline Age (years) & $51.50 \pm 16.57$ & $61.41 \pm 19.06$ & 0.008 \\
\hline Gender & & & 0.138 \\
\hline Male & 45 & 17 & \\
\hline Female & 56 & 10 & \\
\hline BMI & $24.44 \pm 4.06$ & $24.02 \pm 3.41$ & 0.650 \\
\hline $\operatorname{GFR}\left(\mathrm{mL} / \mathrm{min} / 1.73 \mathrm{~m}^{2}\right)$ & $77.52 \pm 26.95$ & $21.93 \pm 9.36$ & 0.000 \\
\hline PASP $(\mathrm{mmHg})$ & $31.31 \pm 7.81$ & $36.33 \pm 10.10$ & 0.022 \\
\hline $\mathrm{PH}(\mathrm{N}, \%)$ & $24(23.76)$ & $13(48.15)$ & 0.013 \\
\hline MAP (mmHg) & $149.44 \pm 27.86$ & $163.67 \pm 36.96$ & 0.049 \\
\hline $\operatorname{lnBNP}(\mathrm{pg} / \mathrm{mL})$ & $3.20 \pm 1.52$ & $4.60 \pm 1.75$ & 0.001 \\
\hline $\mathrm{LA}(\mathrm{mm})$ & $39.54 \pm 5.81$ & $42.19 \pm 5.96$ & 0.039 \\
\hline LVDd (mm) & $48.29 \pm 3.81$ & $50.42 \pm 4.92$ & 0.298 \\
\hline LVDs (mm) & $31.59 \pm 5.22$ & $33.911 \pm 5.32$ & 0.183 \\
\hline IVST (mm) & $9.53 \pm 1.53$ & $10.19 \pm 1.80$ & 0.059 \\
\hline LVPW (mm) & $9.39 \pm 2.30$ & $9.39 \pm 1.90$ & 0.268 \\
\hline LVEF & $0.64 \pm 0.06$ & $0.62 \pm 0.05$ & 0.069 \\
\hline $\operatorname{LVMI}\left(\mathrm{g} / \mathrm{m}^{2}\right)$ & $99.93 \pm 30.81$ & $113.09 \pm 38.91$ & 0.086 \\
\hline
\end{tabular}

BMI = body mass index; GFR = glomerular filtration rate; PASP = pulmonary artery systolic pressure; PH = pulmonary hypertension; MAP = mean artery blood pressure; LA = left atrial diameter; LVDd = left ventricle end-diastolic diameter; LVDs = left ventricle end-systolic diameter; IVST = interventricular septum thickness; LVPW = left ventricular posterior wall thickness; LVEF = left ventricular ejection fraction; LVMI = left ventricular myocardial mass index. Results are reported as means \pm standard deviation.

Table 2. Comparison of patients with and without pulmonary hypertension.

\begin{tabular}{|c|c|c|c|}
\hline Variables & $\mathrm{PASP}<35 \mathrm{mmHg}$ & $\mathrm{PASP} \geq 35 \mathrm{mmHg}$ & $P$ value \\
\hline No. of patients (\%) & $91(71.09)$ & $37(28.91)$ & \\
\hline Age (years) & $48.88 \pm 16.15$ & $65.16 \pm 15.39$ & 0.000 \\
\hline Gender & & & 0.074 \\
\hline Male & 39 & 23 & \\
\hline Female & 52 & 14 & \\
\hline BMI & $24.74 \pm 3.42$ & $23.35 \pm 4.92$ & 0.088 \\
\hline $\operatorname{GFR}\left(\mathrm{mL} / \mathrm{min} / 1.73 \mathrm{~m}^{2}\right)$ & $75.59 \pm 31.62$ & $44.10 \pm 22.90$ & 0.000 \\
\hline MAP $(\mathrm{mmHg})$ & $146.99 \pm 28.53$ & $166.15 \pm 31.46$ & 0.004 \\
\hline $\operatorname{lnBNP}(\mathrm{pg} / \mathrm{mL})$ & $2.89 \pm 1.29$ & $4.93 \pm 1.60$ & 0.000 \\
\hline $\mathrm{LA}(\mathrm{mm})$ & $37.76 \pm 7.48$ & $43.94 \pm 5.81$ & 0.000 \\
\hline LVDd (mm) & $49.53 \pm 4.57$ & $53.19 \pm 5.56$ & 0.000 \\
\hline LVDs (mm) & $31.04 \pm 4.76$ & $34.11 \pm 5.84$ & 0.003 \\
\hline IVST (mm) & $9.31 \pm 1.40$ & $10.58 \pm 1.73$ & 0.000 \\
\hline LVPW (mm) & $9.24 \pm 2.32$ & $10.17 \pm 1.84$ & 0.034 \\
\hline LVEF & $0.65 \pm 0.06$ & $0.60 \pm 0.05$ & 0.000 \\
\hline LVMI (g/m²) & $92.83 \pm 22.46$ & $127.81 \pm 41.45$ & 0.000 \\
\hline
\end{tabular}

PASP = pulmonary artery systolic pressure; BMI = body mass index; GFR = glomerular filtration rate; PH = pulmonary hypertension; MAP = mean artery blood pressure; LA = left atrial diameter; LVDd = left ventricle end-diastolic diameter; LVDs = left ventricle end-systolic diameter; IVST = interventricular septum thickness; LVPW = left ventricular posterior wall thickness; LVEF = left ventricular ejection fraction; LVMI = left ventricular myocardial mass index. Results are reported as means \pm standard deviation. 


\begin{tabular}{lcr}
\multicolumn{2}{c}{ Table 3. Pulmonary artery systolic pressure risk factors. } & P value \\
\hline & $\mathrm{T}$ & 0.000 \\
\hline GFR & -0.488 & 0.000 \\
Age & 0.496 & 0.000 \\
MAP & 0.398 & 0.000 \\
lnBNP & 0.651 & 0.000 \\
LA & 0.595 & 0.003 \\
LVDd & 0.404 & 0.005 \\
LVDs & 0.377 & 0.001 \\
IVST & 0.457 & 0.001 \\
LVPW & 0.431 & 0.011 \\
LVEF & -0.338 & 0.000 \\
LVMI & 0.382 & \\
\hline
\end{tabular}

For abbreviations, see legend to Table 1.

A

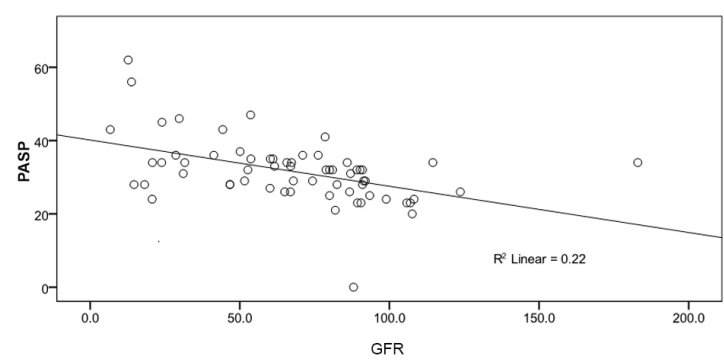

C

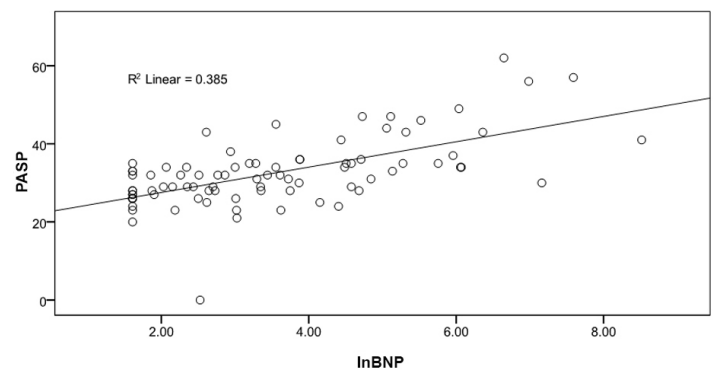

B

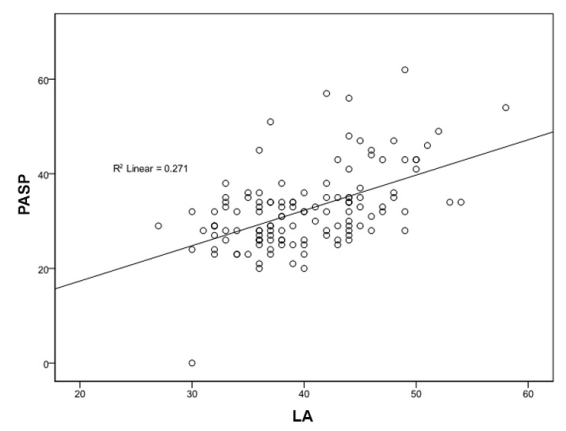

Figure 1. Pulmonary artery systolic pressure (PASP) of 128 patients with predialysis chronic kidney disease was independently correlated with mean values of $\operatorname{lnBNP}$, left atrial diameter and glomerular filtration rate (GFR) by linear regression analysis. A. Negative correlation between PASP and GFR. B. Positive correlation between left atrial (LA) diameter and PASP. C. Negative correlation between PASP and lnBNP.

\section{DISCUSSION}

PH is a clinical syndrome characterized by elevated pulmonary artery pressure and vascular resistance. Elevation of pulmonary artery pressure is often superior to clinical history and physical examination (Himelman et al., 1988; Rich, 1988). Strictly, PH is defined as a mean pulmonary artery pressure exceeding $25 \mathrm{mmHg}$ at rest, or $30 \mathrm{mmHg}$ during exercise by right-sided cardiac catheterization (Badesch et al., 2009). Echo-Doppler estimated PASP, 
a commonly applied non-invasive measurement, plays a key role in the diagnosis, prognosis and follow-up of patients with PH. Under Doppler echocardiography studies, measurement of PASP is based on the tricuspid regurgitation jet. In the absence of pulmonary stenosis, right ventricular systolic pressure, or PASP, is estimated using a modified Bernoulli equation and is computed as 4 times the square of the maximum tricuspid regurgitation jet velocity, plus right atrial pressure (which in turn can be estimated from the vena cava diameter and degree of its inspiratory collapse) (Rudski et al., 2010). Often, a fixed estimate of right atrial pressure is added when the inferior vena cava is not evaluated during echocardiography. Varied cutoffs of $\mathrm{PH}$ have been adopted in studies, ranging from 25 to $\geq 45 \mathrm{mmHg}$ (Yigla et al., 2009; Kiykim et al., 2010), which result in different conclusions about PH prevalence. Here, we adopted the $\mathrm{PH}$ diagnostic criteria as a PASP $\geq 35 \mathrm{mmHg}$ (Buemi et al., 2007).

$\mathrm{PH}$ comprises a group of clinical and pathophysiological entities with similar features, but various underlying causes, including CKD (Havlucu et al., 2007; Domenici et al., 2010). The prevalence of $\mathrm{PH}$ ranges from 9-39\% in predialysis patients with stage-5 CKD (Yigla et al., 2003; Buemi et al., 2007; Havlucu et al., 2007; Abdelwhab and Elshinnawy, 2008; Issa et al., 2008), 18.8-68.8\% in hemodialysis patients, and $0-42 \%$ in individuals on peritoneal dialysis therapy (Kumbar et al., 2007; Bozbas et al., 2009; Unal et al., 2009; Casas-Aparicio et al., 2010; Kiykim et al., 2010; Fabbian et al., 2011; Agarwal, 2012; Etemadi et al., 2012). In our study, 37 of 128 (28.91\%) CKD patients from China, who accepted no dialysis or renal transplantation, had Doppler-derived PASP $\geq 35 \mathrm{mmHg}$. Thus, $\mathrm{PH}$ incidence in predialysis CKD cases reached $28.91 \%$, in accordance with data reported above. Given that other conditions related to $\mathrm{PH}$ were strictly excluded in advance, we reconfirmed that CKD led to PH. Essential Doppler measurement and careful attention should be taken to identify this PH phenomenon. Studies on PH have been performed in patients who either reached end stage of renal disease or accepted renal replacement therapy, however, few focused on patients with earlier stages of CKD. In our study, differences were uncovered between patients in GFR $\geq 60 \mathrm{~mL} / \mathrm{min} / 1.73 \mathrm{~m}^{2}$ group and patients in GFR $<60 \mathrm{~mL} / \mathrm{min} / 1.73$ $\mathrm{m}^{2}$ group. Although PH prevalence reached $48.15 \%$ (13/27) in the GFR $<60 \mathrm{~mL} / \mathrm{min} / 1.73$ $\mathrm{m}^{2}$ group, the GFR $\geq 60 \mathrm{~mL} / \mathrm{min} / 1.73 \mathrm{~m}^{2}$ group (with less renal injury) still has a prevalence of $23.76 \%, 24$ of $101 \mathrm{CKD}$ patients. It raises the alarm that PH exists and may be prevalent prior to a drop in the GFR to $60 \mathrm{~mL} / \mathrm{min} / 1.73 \mathrm{~m}^{2}$.

We observed differences between patients with and without $\mathrm{PH}$ according to age, MAP, GFR, InBNP, and echocardiography (LA, LVDd, LVDs, IVST, LVPW, LVEF, LVMI). This implies that pulmonary artery pressure is determined by a diverse set of complex factors in CKD patients.

$\mathrm{BNP}$, a hormone mainly produced and released in the left ventricle as a consequence of pressure or volume load, is believed to be involved in PH. It was reported that BNP was related to PASP in primary PH (Leuchte et al., 2004), and a supplementary dose of BNP reduces PASP levels (Cargill and Lipworth, 1995). BNP is a sensitive and specific predictor of LV systolic failure (Vasan et al., 2002), a very useful tool to confirm LV diastolic dysfunction (LVEF $\geq 45-50 \%$ ) (Wei et al., 2005) and is in accordance with volume overload (Kunii et al., 2003) at the same time. Plasma BNP increased with loss of renal function (Lang et al., 1992). In this study, we noticed in patients of chronic kidney disease a significant positive correlation between PASP and lnBNP. It suggests that BNP plays an important role in pulmonary hypertension secondary to kidney disease. We found that the LVMI, an indication for LV hypertrophy, increased in accordance to plasma BNP, and there was no value of LVEF (the 
minimum value is $48 \%$ in our study) below $45 \%$. Thus, volume overload, implicated in LV disorders and in the high venous return, and LV diastolic dysfunction, an alteration found in patients with CKD to increase pulmonary venous and arterial pressure (Tiengo et al., 2008), may together induce PH by increasing pulmonary blood flow and adversely affecting LV function.

In addition to BNP, the LA was the second important factor determining the PASP independently. We observed larger values of LVMI in patients with PH. LV hypertrophy causes diastolic disorder of the left ventricle, which is then followed by an increase in LA. Then, pulmonary circulation is pulled into a high pressure network, followed by upregulated pulmonary venous pressure (Tiengo et al., 2008), and finally, pulmonary artery hypertension.

The decrease in kidney function may be a trigger for the development of PASP disturbance. GFR was negatively correlated with PASP in our study. The Doppler-estimated PASP increased inversely to renal function. In kidney disease, a series of complications appears eventually, such as anemia, endothelial dysfunction, LV dysfunction, and volume overload. Severe anemia, an established cardiovascular risk factor in CKD, may extend its impact to pulmonary circulation. Low hemoglobin levels may contribute to PH by aggravating hypoxia triggered by concomitant conditions (Buemi et al., 2007). Endothelial dysfunction is a main trigger of pulmonary hypertension (Giaid, 1998). This link is even close in CKD patients, whose endothelial dysfunction is pervasive (Zoccali, 2007). The impaired capacity of the endothelium to regulate vascular tone in CKD patients relies on a disturbance between vasoconstrictors (e.g., high levels of endothelin 1) and vasodilators [reduced generation of nitric oxide (NO)] (Giaid and Saleh, 1995; Kunii et al., 2003). ADMA, an endogenous inhibitor of NO synthase, attains very high concentrations in patients with kidney disease (Zoccali et al., 2001). Our continuing studies will uncover the issues of anemia, endothelin 1/NO and other relevant conditions in early stages of CKD.

In a general population based study (Lam et al., 2009), PASP was related directly to age and systolic pressure in patients over 45 years old, which suggests that pulmonary artery stiffening plays a role in the development of PH. Through our study in CKD patients, the level of PASP elevated in the same direction as aging and MAP. Therefore, pulmonary artery stiffening, the aging process, and systemic blood pressure all contribute to $\mathrm{PH}$. However, the influence was confined to some extent, and the efficacy faded with progression of renal disease.

Based on our observations, we conclude that a substantial number of early stage CKD patients with GFR $\geq 60 \mathrm{~mL} / \mathrm{min} / 1.73 \mathrm{~m}^{2}$ have a functional abnormality of pulmonary circulation. Plasma BNP, GFR, and LA, all impose an independent influence on Doppler-estimated PASP. Estimation and follow-up of PASP using echocardiography may be required in CKD patients even when GFR $\geq 60 \mathrm{~mL} / \mathrm{min} / 1.73 \mathrm{~m}^{2}$. Periodic measurement of plasma BNP may be a valuable predictor for monitoring the progression of $\mathrm{PH}$ in early stages of $\mathrm{CKD}$.

\section{Limitations of the study}

The sample size of this study is relatively small, and for this reason, large multicenter studies are required to confirm our findings. Pulmonary systolic artery pressure was noninvasively measured using Doppler echocardiography without obtaining right heart catheterization. In addition, we did not collect follow-up data to evaluate the effect of PH on morbidity and mortality. Further investigations in a large number of stage 1-3 CKD (according to $\mathrm{KDOQI}$ ) patients with $\mathrm{PH}$ are needed. Long-term follow-up is essential for future studies. 


\section{ACKNOWLEDGMENTS}

Research supported by the Shanghai Municipal Commission of Health and Family Planning (grant \#2012-254).

\section{REFERENCES}

Abdelwhab S and Elshinnawy S (2008). Pulmonary hypertension in chronic renal failure patients. Am. J. Nephrol. 28: 990-997.

Agarwal R (2012). Prevalence, determinants and prognosis of pulmonary hypertension among hemodialysis patients. Nephrol. Dial. Transplant. 27: 3908-3914.

Badesch DB, Champion HC, Sanchez MA, Hoeper MM, et al. (2009). Diagnosis and assessment of pulmonary arterial hypertension. J. Am. Coll. Cardiol. 54: S55-S66.

Berger M, Haimowitz A, Van Tosh A, Berdoff RL, et al. (1985). Quantitative assessment of pulmonary hypertension in patients with tricuspid regurgitation using continuous wave Doppler ultrasound. J. Am. Coll. Cardiol. 6: 359-365.

Bozbas SS, Akcay S, Altin C, Bozbas H, et al. (2009). Pulmonary hypertension in patients with end-stage renal disease undergoing renal transplantation. Transplant. Proc. 41: 2753-2756.

Buemi M, Senatore M, Gallo GC, Crasci E, et al. (2007). Pulmonary hypertension and erythropoietin. Kidney Blood Press Res. 30: 248-252.

Cargill RI and Lipworth BJ (1995). Acute effects of ANP and BNP on hypoxic pulmonary vasoconstriction in humans. Br. J. Clin. Pharmacol. 40: 585-590.

Casas-Aparicio G, Castillo-Martínez L, Orea-Tejeda A, Abasta-Jiménez M, et al. (2010). The effect of successful kidney transplantation on ventricular dysfunction and pulmonary hypertension. Transplant. Proc. 42: 3524-3528.

Domenici A, Luciani R and Principe F (2010). Pulmonary hypertension in dialysis patients. Perit. Dial. Int. 30: 251-252.

Etemadi J, Zolfaghari H, Firoozi R, Ardalan MR, et al. (2012). Unexplained pulmonary hypertension in peritoneal dialysis and hemodialysis patients. Rev. Port. Pneumol. 18: 10-14.

Fabbian F, Cantelli S, Molino C, Pala M, et al. (2011). Pulmonary hypertension in dialysis patients: a cross-sectional italian study. Int. J. Nephrol. 2011: 1-4.

Giaid A (1998). Nitric oxide and endothelin-1 in pulmonary hypertension. Chest 114: 208S-212S.

Giaid A and Saleh D (1995). Reduced expression of endothelial nitric oxide synthase in the lungs of patients with pulmonary hypertension. N. Engl. J. Med. 333: 214-221.

Havlucu Y, Kursat S, Ekmekci C and Celik P (2007). Pulmonary hypertension in patients with chronic renal failure. Respiration 74: 503-510.

Himelman RB, Struve SN, Brown JK, Namnum P, et al. (1988). Improved recognition of cor pulmonale in patients with severe chronic obstructive pulmonary disease. Am. J. Med. 84: 891-898.

Issa N, Krowka MJ, Griffin MD, Hickson LJ, et al. (2008). Pulmonary hypertension is associated with reduced patient survival after kidney transplantation. Transplantation 86: 1384-1388.

Kiykim AA, Horoz M, Ozcan T, Yildiz I, et al. (2010). Pulmonary hypertension in hemodialysis patients without arteriovenous fistula: the effect of dialyzer composition. Ren. Fail. 32: 1148-1152.

Kumbar L, Fein PA, Rafiq MA, Borawski C, et al. (2007). Pulmonary hypertension in peritoneal dialysis patients. $A d v$. Perit. Dial. 23: 127-131.

Kunii Y, Kamada M, Ohtsuki S, Araki T, et al. (2003). Plasma brain natriuretic peptide and the evaluation of volume overload in infants and children with congenital heart disease. Acta Med. Okayama 57: 191-197.

Lam CS, Borlaug BA, Kane GC, Enders FT, et al. (2009). Age-associated increases in pulmonary artery systolic pressure in the general population. Circulation 119: 2663-2670.

Lang CC, Choy AM, Henderson IS, Coutie WJ, et al. (1992). Effect of haemodialysis on plasma levels of brain natriuretic peptide in patients with chronic renal failure. Clin. Sci. 82: 127-131.

Leuchte HH, Holzapfel M, Baumgartner RA, Ding I, et al. (2004). Clinical significance of brain natriuretic peptide in primary pulmonary hypertension. J. Am. Coll. Cardiol. 43: 764-770.

Reisner SA, Azzam Z, Halmann M, Rinkevich D, et al. (1994). Septal/free wall curvature ratio: a noninvasive index of pulmonary arterial pressure. J. Am. Soc. Echocardiogr. 7: 27-35.

Rich S (1988). Primary pulmonary hypertension. Prog. Cardiovasc. Dis. 31: 205-238.

Rudski LG, Lai WW, Afilalo J, Hua L, et al. (2010). Guidelines for the echocardiographic assessment of the right heart in adults: a report from the American Society of Echocardiography endorsed by the European Association 
of Echocardiography, a registered branch of the European Society of Cardiology, and the Canadian Society of Echocardiography. J. Am. Soc. Echocardiogr. 23: 685-713.

Sakaguchi Y, Shoji T, Kawabata H, Niihata K, et al. (2011). High prevalence of obstructive sleep apnea and its association with renal function among nondialysis chronic kidney disease patients in Japan: a cross-sectional study. Clin. J. Am. Soc. Nephrol. 6: 995-1000.

Tiengo A, Fadini GP and Avogaro A (2008). The metabolic syndrome, diabetes and lung dysfunction. Diabetes Metab. 34: 447-454.

Unal A, Sipahioglu M, Oguz F, Kaya M, et al. (2009). Pulmonary hypertension in peritoneal dialysis patients: prevalence and risk factors. Perit. Dial. Int. 29: 191-198.

Vasan RS, Benjamin EJ, Larson MG, Leip EP, et al. (2002). Plasma natriuretic peptides for community screening for left ventricular hypertrophy and systolic dysfunction: the Framingham heart study. JAMA 288: 1252-1259.

Wei T, Zeng C, Chen L, Chen Q, et al. (2005). Bedside tests of B-type natriuretic peptide in the diagnosis of left ventricular diastolic dysfunction in hypertensive patients. Eur. J. Heart Fail. 7: 75-79.

Yigla M, Nakhoul F, Sabag A, Tov N, et al. (2003). Pulmonary hypertension in patients with end-stage renal disease. Chest 123: 1577-1582.

Yigla M, Fruchter O, Aharonson D, Yanay N, et al. (2009). Pulmonary hypertension is an independent predictor of mortality in hemodialysis patients. Kidney Int. 75: 969-975.

Zoccali C (2007). The endothelium as a target in renal diseases. J. Nephrol. 20 (Suppl 12): S39-S44.

Zoccali C, Bode-Böger S, Mallamaci F, Benedetto F, et al. (2001). Plasma concentration of asymmetrical dimethylarginine and mortality in patients with end-stage renal disease: a prospective study. Lancet 358: 2113-2117. 